\title{
Assessing How Perceived Inclusion Affects Minority Employees' Organizational Satisfaction in higher Education Institutions in the U.S.
}

\author{
Abdelfatah S. Arman
}

\section{ABSTRACT}

In the present study, the author examines how perceived inclusion affects minority employees' organizational satisfaction in higher education institutions in the United States. A quantitative exploratory approach was used for this study. The methodology involves measuring the relationship between minority status and job satisfaction for employees in higher education institutions in the U.S. if any, and the relationship between minority employees' status and their perception of inclusion in their workgroups. Data was collected using an online panel survey of higher education employees in the United States using Amazon's Mechanical Turk (MTurk); a crowdsourcing platform. A sample size of $(N=1,898)$ subjects were sought to complete the online survey. The present study's results illustrate a new finding which was that when comparing minority groups engaged in higher education organizations with their minority peers employed at a Historically Black College or University (HBCU) or other minority-serving institutions, minority individuals employed in higher education institutions felt less included and satisfied than the ones involved in HBCU or other minority catering organizations. Findings demonstrate there is a statistically significant positive correlation between inclusion and workplace satisfaction. The results also show there are differences in inclusion by demographic status, sexual orientation, disability status, religion, and type of workplace. The study's results reveal that minority groups employed in higher education organizations have a low sense of belonging, which may result in dissatisfaction with the workplace and eventually force them to quit their jobs.

Keywords: diversity, job satisfaction, higher education, workplace inclusion, minority groups.

\section{INTRODUCTION}

In today's extremely competitive global market, organizations are striving to attain any advantage that can provide them with an edge over their competitors. The United States, in recent years, has undergone demographic shifts with the rapid growth of immigration; more than 23 million immigrants replanting themselves into the U.S. between 1990 and 2016 [1]. These demographic trends that are rapidly materializing globally, provide employers with an opportunity to attract talent from a diverse pool of candidates both domestically and internationally [2]. Concurrently, such swift demographic trends compel higher education organizations in the U.S. to change their business models to address these unprecedented challenges in ways that ensure the organizational systems, structures, cultures, and reward systems are aligned with the organization's strategic goals.

Globalization has presented the United States higher education organizations with an opportunity to compete and attract staff, faculty, and students internationally. Hazelkorn [3] indicated that the internationalization of the education
Submitted : August 21, 2021

Published : September 12, 2021

ISSN: $2507-1076$

DOI: $10.24018 /$ ejbmr.2021.6.5.1067

Abdelfatah S. Arman PhD*

Assistant Professor of Human Resources Management, Department of Management, School of Business Administration, American University of Ras Al Khaimah, Ras Al Khaimah, United Arab Emirates.

(e-mail: abdelfatah.arman@aurak.ac.ae)

*Corresponding Author enterprise had become both a government and a higher education organization's priority because it is viewed as a global competitive advantage. Chun and Evans [4] pointed out that globalization should catalyze change in the higher education enterprise, as it eliminates economic, cultural, and national boundaries by transforming how an organization serves its stakeholders. This phenomenon presented higher education institutions with a responsibility to cater to diverse stakeholders by changing their business models, not only by developing an inclusive learning environment but also by promoting diversity and inclusion of faculty, students, and staff. Colleges are significant providers of training in a variety of fields. As such, higher education organizations play a critical role not only in the creation and distribution of knowledge but are also significant contributors socially, culturally, and economically in society [5].

In 2015, women in the U.S. were the majority of the workforce, at $52 \%$ (U.S. Bureau of Labor Statistics), and by the year 2032, employees of color will be the mainstream workforce in the U.S. [6]. Furthermore, globalization has played a pivotal role in transforming the workforce into a 
more internationalized labor force with $76 \%$ of the world's population presently existing in Africa and Asia [7]. The workforce is changing rapidly, and the techniques by which organizations attract, recruit, hire, and retain talent should change along with it. Diversity requires talent developers and managers to utilize strategies to retain top talent by implementing inclusive workplace practices. Kuchinke [8] argued that organizations have an ethical and moral obligation to develop workers as human beings in addition to developing them as human resources to achieve their strategic goals. Scholars have focused their research efforts on diversity in the workplace, but have not studied inclusion until recently. Thus, a gap exists in the literature on inclusion [9].

However, in the context of the U.S., there is a lacuna in the literature of higher education organizations when it comes to inclusion in the workplace and the correlation of minority group staff's feelings of inclusion and its impact on job satisfaction. The previous studies have been conducted on minority faculty, graduate, and undergraduate students' perceived inclusion in higher education institutions; however, researchers overlooked the relationship of perceived inclusion and job satisfaction of minority group employees in higher education institutions. Therefore, the present study aimed to examine how perceived inclusion affects minority employees' organizational satisfaction in higher education institutions in the United States. The author uses the term minority groups to refer to African Americans, Hispanics, immigrants, women, religious minority groups, disabled persons, and those who identify as lesbian, gay, bisexual, and transgender (LGBTQ) employees of higher education institutions.

\section{REVIEW OF RELATED LITERATURE}

\section{A. Workplace Inclusion}

Mor Barak [10] used the term inclusive workplace to refer to "a work organization that accepts and utilizes the diversity of its workforce while being active in the community" (p. 8). Inclusion in the workplace deals with how employers, groups; their leaders, and members use practices that grant all employees to actively be involved, contribute, speak out, and feel that they're engaged and belong, without losing their unique identities or some aspects of what makes them who they are [11]. Mor-Barak [12] pointed out that on a personal level, an inclusive workplace for employees can be viewed in three ways: (1) being a part of the essential organizational processes such as access to resources and information network, (2) being included in the decision-making process, and (3) whether workers' participation level is high in workgroups.

On the organizational level, Mor Barak [12] argued that an inclusive workplace is the one that: (1) values and uses worker and intergroup differences within the organization, (2) collaborates with and gives to its neighboring community, (3) mitigates the needs of underprivileged groups in its surrounding areas, and (4) cooperates with people domestically and globally. While Ferdman [13] indicated that "in inclusive organizations and societies, people of all identities and many styles can be fully themselves while also contributing to the larger collective, as valued and full members" (p. 235). Therefore, an inclusive organization permits, facilitates, and promotes the inclusion of individual workers who are dissimilar from the majority in the workplace's decision-making processes and social networks [14].

Organizations are witnessing an increase in workforce diversity that led their leaders to pay attention to designing an inclusive climate for their workers [15].

However, the literature on workplace inclusion is lacking [16]. Bhopala and Rhamieb [17] claimed that research on diversity and inclusion in higher education was underdeveloped. The authors examined relatedness and exclusion, which existed in the U.K; the findings indicated that more training is needed to ensure that universities are using inclusive practices within their educational environments. Tienda [18] argued that the United States. higher education institutions are positioned to take the lead in fostering inclusive environments for students, staff, and faculty. The educational enterprise can demonstrate to its stakeholders that creating an inclusive climate for everyone serves the country's national interests.

\section{B. Organizational Demography Research on Inclusion}

Research on organizational demography focuses on characteristics that affect social dynamics, which impact organizational outcomes. Such outcomes are highly influenced by the demographic composition of work groups. Previous studies demonstrated that demographic heterogeneity, especially regarding observable characteristics, lowers an employee's sense of belonging to the group and thus increases voluntary turnover intentions [19]. Mor Barak [12] indicated that research on organizational demography demonstrates that being a minority in the workplace has a profound impact on employee experiences in the workplace, including feelings of alienation and lack of uniformity in personal relationships with co-workers.

According to Mor Barak [10], one of the most regularly reported issues encountered by minority groups in the workplace is their lack of access to or insularity to significant networks of informal interactions. Also, the author indicated women in the workplace faced another obstacle, which is they are experiencing minimal access to organizational informal social networks. African American women interviewed by Mor Barak [12] stated they felt they lacked access to informal social networks in their workplaces more than White men and women. Chun and Evans [4] reported that faculty members and women staff from minority groups in higher education organizations in the U.S. feel excluded from critical organizational processes. Bringing those minority groups from the organizational periphery to the center stage would help the organization improve its effectiveness to achieve its strategic objectives.

\section{Social Identity Theory (SIT)}

In 1972, Tajfel coins social identity as "the individual's knowledge that he belongs to certain social groups together with some emotional and value significance to him of the group membership" (p. 292). SIT was the first social psychological model to recognize that "groups occupy different levels of a hierarchy of status and power, and that 
intergroup behaviour is driven by people's ability to be critical of, and to see alternatives to, the status quo" [20, p. 207]. When applying SIT to the U.S. higher education organizations, the theory demonstrates when minority groups in these universities perceive they have a low social status in their workgroups, they strive to do their best to change the status of their workgroup identities by ascribing positive attributes to its distinctive elements [21].

Hewapathirana [22] utilized SIT to investigate examines the effect of organizational leaders' social identity on themselves and their workers' motivation in Sri Lankan organizations. The results indicate that leaders' social identities turn into an inner psychological power that forms the behaviors, perceptions, and beliefs of themselves and their workers. The study suggests that SIT can be employ as a foundation for sustaining a culture of excellence and developing human resource approaches to foster an organizational culture of collaboration and innovation.

Ryan and Deci's [23] Self-Determination Theory (SDT) indicates that there are three psychological needs for all people, which are the need for competence, relatedness, and autonomy. The satisfaction of these three basic needs should bring favorable results to individuals. Deci and Ryan [23] defined relatedness or belongingness as "people feel relatedness most typically when they feel cared for by others. A sense of being integral to social organizations beyond oneself' (p. 11). The SDT's central premise on relatedness is aligned with, therefore, there is a link between the level of inclusion a worker feels in the organization and satisfaction with the workplace [12].

\section{METHODS}

A quantitative exploratory approach was used for this study. The methodology involved measuring the relationship between minority status and job satisfaction for employees in higher education institutions in the U.S., if any, and the relationship between minority employees' status and their perception of inclusion in their workgroups. The research questions guiding this study are as follows:

RQ1: What, if any relationship exists between inclusion and job satisfaction for employees in higher education?

RQ1a: Does minority status affect workplace inclusion for employees in higher education?

RQ1b: Does minority status affect job satisfaction for employees in higher education?

To collect the data needed to address these questions, the researcher conducted an online panel survey of higher education employees in the United States using Amazon's Mechanical Turk (MTurk). The quality of MTurk compared to other instruments is that participants can be drawn internationally and across the U.S., and they are "demographically diverse than standard Internet samples and significantly more diverse than typical American college samples" [24, p. 4]. Mason and Suri [25] stated that some of MTurk's advantages are that researchers have access to participant pool access, diverse subjects, and inexpensive to recruit research participants.

\section{A. Participants}

Based on a population of about 4 million people working in higher education organizations in the U.S. [26], using a $95 \%$ confidence level and a confidence interval of 5, a power analysis gave the researcher a sample size of 384 . Nevertheless, to ensure an inclusive representation of all demographics and subgroups employed in the U.S. higher education organizations, 1,898 subjects were surveyed. A sample size of $(N=1,898)$ subjects was sought to complete the online survey. To compare inclusion/exclusion and how it affects minority groups in higher education organizations in the U.S., a representative sample of the minority respondents $(n=949)$ with a similar sample from the majority respondents $(n=949)$, a total sample of 1,898 subjects were drawn from MTurk platform. Eligibility criteria for the minority panel included employment in higher education in the United States and identification as one or more minority groups based on race, ethnicity, gender, religion, being foreign born, and/or sexual orientation. For the second panel, study participants must be working in higher education in the U.S. and Caucasian males, because they are the majority employed by higher education organizations in the U.S. The study was approved for human subjects research by the Institutional Review Board the Pennsylvania State University.

\section{B. Demographic Variables}

Demographic variables included in this study are selfreported social identity, demographics, sexual orientation, disability status, religious affiliation, country of birth, and type of place of employment. The author was interested in these demographic variables to ensure that inclusivity by including these demographic variables, especially by including subgroups such as race, religion, sexual orientation, persons with a disability, and gender minorities.

\section{Instrument}

The Mor Barak inclusion-exclusion scale (MBIE) (2005) was used to operationalize the study inclusion variable. The measure includes 15 items that assess an employee's sense of inclusion in connection to the five work-organization system levels. The survey was designed to measure the degree to which people feel a part of essential organizational processes, such as involvement and participation with the workplace, influence in the decision-making process, and access to information. It comprises five work-organization system elements (workgroup, organization, supervisor, higher management, and social/informal) divided by three inclusion components (information networks, decision making, and participation/involvement). Job satisfaction items included in the survey were adapted from the Michigan Organizational Assessment Questionnaire Job Satisfaction Subscale (MOAQ-JSS). For this study, the researcher added 13 more items to the survey such as an eligibility screener to ensure that only individuals who are currently working for higher education institutions in the United States complete the survey and to capture data on social identity and demographics, disability status, religious affiliation, and so on (Consortium of Higher Education, n.d.). The questions about gender identity and sexual orientation came from the Consortium of Higher Education's best practices guidelines. Fifteen questions about employee perceptions of inclusion were adapted from the MBIE scale [27]. Questions about whether respondents 
are satisfied with their current jobs were adapted from the MOAQ-JSS. Disability questions came from the United States Census Bureau [28].

\section{Data Analysis}

A total of $(N=1,898)$ participants were recruited for this study. However, during the coding and cleaning of the collected data, the researcher found that there was a total of 174 incomplete or disingenuous responses, which were discarded. Therefore, a total of 1,724 responses were coded and analyzed for this study. Inclusion items: 5, 8, and 15 were reverse scored then 1-15 were added up. Also, Job Satisfaction items 17 were reverse scored, and then 16-18 were summed. First, to determine the relationship between inclusion and job satisfaction without consideration of demographics, the researcher conducted a correlational test to establish the correlation between inclusion and job satisfaction, if any. Second, the researcher ran an analysis of variance for items numbers 19, 20, 22, 25, and 26 (gender, race, sexual orientation, disability status, and religious affiliation) to determine if there were any differences between inclusion by minority status. Third, the author ran an Independent Samples $t$-test to compare the means of the White males group with the minority group for items 21 and 27 as independent groups to determine whether there was statistical evidence that the related population means were significantly different in terms of inclusion. Fourth, an analysis of variance was conducted for items numbers 19 , 20, 22, 25 and 26 (gender, race, sexual orientation, disability status, and religious affiliation) to determine the differences between job satisfaction by minority status. Fifth, concerning job satisfaction, an Independent Samples $t$-test was run to compare the means of the White males group with the minority group for items 21 (identity as Hispanic/Latino) and 27 (description of self concerning religion) as independent groups to determine whether there was statistical evidence that the associated population means are significantly different. Seventh, foreign-born status was assessed by the $t$-test.

\section{RESULTS}

Table I provides the descriptive statistics for the means and the differences from the means in terms of inclusion and satisfaction for all demographic variables included in this study. The largest proportion of study participants selfreported as White $(n=1150)$, followed by Black or African American ( $n=389)$, Asian $(n=175)$, American Indian or Alaskan Native $(n=48)$, and Native Hawaiian or Other Pacific Islander $(n=5)$, as well as Hispanic/Latino $(n=311)$ and foreign-born participants $(n=117)$. The sample was primarily male $(n=849)$ followed by women $(n=842)$, genderqueer or gender fluid $(n=14)$, androgyne $(n=13)$, questioning or unsure $(n=13)$, agender $(n=12)$, trans-man $(\mathrm{n}=10)$, demigender $(n=9)$, trans-woman $(n=7)$, and participants who preferred not to disclosed gender $(n=5)$. Table I also demonstrates differences from the means for inclusion and satisfaction, results above the mean indicate that people felt more included or satisfied than the average respondent, while findings below the mean reflect exclusion and dissatisfaction in the workplace. A correlation between inclusion and job satisfaction without consideration of demographics reveals that there is a statistically significant positive correlation between inclusion and workplace satisfaction for all employees, $\mathrm{r}(1724)=0.559, p<0.001$.

The study's first research question is whether there is a relationship between inclusion and job satisfaction for employees in higher education organizations. An analysis of the correlation between inclusion and satisfaction presented that there is a statistically significant positive correlation between inclusion and workplace satisfaction for all workers without consideration of demographics. The correlation, $r=$ $0.559, p<0.001$, signifies that there is a very strong relationship between inclusion and satisfaction, which means as inclusion goes up satisfaction does.

The second question is whether minority status affects inclusion for employees in higher education. An analysis of variance showed the differences in inclusion by minority status by race, which disclosed that there are differences between groups and within groups. It demonstrated that there are differences in inclusion by race, $F(10,1766)=$ $0.028, \mathrm{p}=0.023$. For example, White participants were above the mean by (4.99). On the other hand, Black or African American participants were below the mean (-1.85), Hispanic, and Latino respondents were above the mean (3.33). Asians were under the mean (-3.43), and American Indian or Alaskan Native respondents were above the mean by (2.49). Therefore, White participants felt more included than minority groups. An analysis of variance based on gender reflected that when people felt they were being included, they were satisfied, which was significant, $F=$ 4.982, $p<0.001$. In this case, White males felt more included than minority groups. To determine the averages of the two groups based on country of birth, the $t$-test revealed there were no differences in inclusion by minority status by country of birth, $t(-0.069)=1673, p=0.95$.

The third question is whether minority status affects job satisfaction for employees in higher education, an analysis of variance indicated that there are differences in satisfaction by minority status by race, $F(10,1777)=6.94, p<0.001$. White respondents' satisfaction scores were above the mean by (2.31). Black or African American participants were below the mean $(-0.17)$, Hispanic and Latino respondents were above the mean (0.71). Asians were under the mean (-0.18), and American Indian or Alaskan Native respondents were below the mean (-0.32). An analysis of variance showed there are differences in satisfaction by minority status by sexual orientation, $F(10,1777)=4.33, p<0.001$. Bisexual participants were above the mean (1.15), and Straight/heterosexuals were above the mean (0.48). Asexual respondent satisfaction scores were below the mean by (1.24), gay respondents were under the mean (-0.23), lesbians were below the mean $(-1.02)$, and pansexual respondents were under the mean $(-1.05)$.

An analysis of variance indicated that there are marginally significant differences in satisfaction for minority groups with disability status, $F(5,882)=2.22, p=$ 0.050 . It is marginally significant because the $p$-value is equal to 0.05 , but not under the threshold. Nevertheless, based on the type of disability status, the result varies; participants with sensory disability were above the mean (0.52), those with a physical disability were below the mean 
$(-0.08)$, and respondents with a mental disability were under the mean $(-0.56)$.

An analysis of variance demonstrated there are differences in satisfaction by religious affiliation, $F(7,773)$ $=6.04, p<0.001$. Most of the sample had no religious affiliation $(n=536)$, followed by Catholic $(n=535)$, Protestant $(n=356)$, Other religions $(n=156)$, Jewish $(n=53)$, Muslim $(n=50)$, Orthodox $(n=18)$, and 70 respondents preferred not to disclose their religious affiliation. Protestants were above the mean by 0.26 , Catholics were above the mean by 0.38 .
Respondents with no religious affiliation were below the mean by (-0.31), Jews were under the mean by $(-2)$, Muslims under the mean by (-0.89), and participants who chose not to answer were below the mean by $(-0.59)$.

An Independent Samples $t$-test was administered to compare the means for the satisfaction of those who were born in the United States with those with foreign-born status, the data show no statistically significant difference based on country of birth, $t(0.067)=1673, p=0.95$.

TABLE I: MEAN INCLUSION AND JOB SATISFACTION BY DEMOGRAPHIC

\begin{tabular}{|c|c|c|c|c|c|}
\hline & \multirow{2}{*}{ Demographic (N-value) } & \multicolumn{2}{|r|}{ Inclusion } & \multicolumn{2}{|r|}{ Satisfaction } \\
\hline & & Mean & Difference from Mean & Mean & Difference from Mean \\
\hline \multirow{13}{*}{ Gender } & Sample Mean: & 49.88 & - & 9.19 & - \\
\hline & Agender (12) & 41.08 & -8.80 & 6.42 & -2.77 \\
\hline & Androgyne (13) & 34.15 & -6.93 & 5.23 & -1.19 \\
\hline & Demigender (9) & 43.78 & 9.63 & 8.56 & 3.33 \\
\hline & Genderqueeer or gender fluid (14) & 46.86 & 3.08 & 7.43 & -1.13 \\
\hline & Man (849) & 50.30 & 3.44 & 9.23 & 1.80 \\
\hline & Questioning or unsure (13) & 43.08 & -7.22 & 8.85 & -0.38 \\
\hline & Trans-man (10) & 44.90 & 1.82 & 7.30 & -1.55 \\
\hline & Trans-woman (7) & 47.14 & 2.24 & 8.29 & 0.99 \\
\hline & Woman (842) & 50.21 & 3.07 & 9.33 & 1.04 \\
\hline & I identify as [Other] (4) & 39.50 & -10.71 & 6.75 & -2.58 \\
\hline & Prefer not to disclose (5) & 45.60 & 6.10 & 7.00 & 0.25 \\
\hline & White (1150) & 50.59 & 4.99 & 9.31 & 2.31 \\
\hline \multirow{3}{*}{ Race } & Black or African American (389) & 48.74 & -1.85 & 9.14 & -0.17 \\
\hline & American Indian or Alaskan Native (48) & 51.23 & 2.49 & 8.9 & -0.24 \\
\hline & Asian (175) & 47.80 & -3.43 & 8.72 & -0.18 \\
\hline \multirow{5}{*}{ Hispanic/Latino } & Native Hawaiian or Other Pacific Islander (5) & 47.00 & -0.80 & 8.40 & -0.32 \\
\hline & Yes (311) & 50.33 & 3.33 & 9.11 & 0.71 \\
\hline & No (1449) & 49.84 & -0.49 & 9.21 & 0.10 \\
\hline & Asexual (74) & 46.80 & -3.04 & 7.97 & -1.24 \\
\hline & Bisexual (243) & 50.20 & 3.40 & 9.12 & 1.15 \\
\hline \multirow{7}{*}{ Sexual Orientation } & Gay (45) & 47.40 & -2.80 & 8.89 & -0.23 \\
\hline & Straight/Heteromosexual (1210) & 50.36 & 2.96 & 9.37 & 0.48 \\
\hline & Lesbian (31) & 49.94 & -0.42 & 8.35 & -1.02 \\
\hline & Pansexual (23) & 44.39 & -5.55 & 7.30 & -1.05 \\
\hline & Queer (10) & 52.10 & 7.71 & 8.10 & 0.80 \\
\hline & Questioning or unsure (11) & 49.18 & -2.92 & 9.55 & 1.45 \\
\hline & Same-gender loving (5) & 59.40 & 10.22 & 10.6 & 1.05 \\
\hline \multirow{8}{*}{ Disability Status } & I identify as [Other] (80) & 48.08 & -11.32 & 9.10 & -1.50 \\
\hline & Prefer not to disclose (45) & 49.98 & 1.90 & 8.80 & -0.30 \\
\hline & Sensory Disability (102) & 50.82 & 0.84 & 9.32 & 0.52 \\
\hline & Physical Disability (202) & 50.75 & -0.07 & 9.24 & -0.08 \\
\hline & Mental Disability (247) & 47.69 & -3.06 & 8.68 & -0.56 \\
\hline & Self-care Disability (119) & 51.02 & 3.33 & 9.28 & 0.60 \\
\hline & Go-outside-home Disability (87) & 48.55 & -2.47 & 8.87 & -0.41 \\
\hline & Employment Disability (127) & 50.03 & 1.48 & 8.91 & 0.04 \\
\hline \multirow{7}{*}{ Religion } & Protestant (356) & 49.25 & -0.78 & 9.17 & 0.26 \\
\hline & Catholic (535) & 49.15 & -0.10 & 9.55 & 0.38 \\
\hline & Jewish (53) & 51.59 & 2.44 & 7.55 & -2.00 \\
\hline & Orthodox (including Greek or Russian Orthodox) (18) & 48.89 & -2.70 & 9.89 & 2.34 \\
\hline & Muslim (50) & 48.54 & -0.35 & 9.00 & -0.89 \\
\hline & Other religion (156) & 48.92 & 0.38 & 9.34 & 0.34 \\
\hline & No religion $(536)$ & 49.88 & 0.96 & 9.03 & -0.31 \\
\hline \multirow{3}{*}{$\mathrm{HBCU}$} & Prefer not to answer (70) & 48.61 & -1.27 & 8.44 & -0.59 \\
\hline & Yes (325) & 51.26 & 2.65 & 10.99 & 2.55 \\
\hline & No (1453) & 49.58 & -1.68 & 8.78 & -2.21 \\
\hline \multirow{2}{*}{ Country of Birth } & United States (1558) & 49.76 & -.0 .12 & 9.18 & --0.01 \\
\hline & Other (117) & 49.84 & -0.04 & 9.20 & 0.01 \\
\hline
\end{tabular}




\section{DISCUSSION}

The study's findings correlated with what the researcher found in the review of literature, the workplace has a significant effect on worker experiences in the workplace such as feelings of exclusion and lack of uniformity in personal relationships with co-workers. For example, Mor Barak's [12] research on organizational demography revealed that being a minority in the workplace has a significant impact on workers' experiences in the workplace, including feelings of exclusion, which is consistent with this study's results. Also, the results are aligned with the review of the literature regarding white males experiencing more inclusion and more satisfaction with the workplace than minority groups who felt less included and less satisfied with their work. Such findings are consistent with Smith and Calasanti's [29] study on social and institutional isolation and how some employers' practices marginalized minority employees.

There is evidence that participants whose religious affiliation is linked with the mainstream religion in the U.S. tend to have greater satisfaction than those who are considered a religious minority, such as Jews and Muslims. An additional observation is that people with no religious affiliation tend to experience less satisfaction than those affiliated with the majority's religions. Byrad, Lear, and Schwenka [30] argued that there is a positive relationship between individuals' religious affiliation and their job satisfaction. The study's findings are also consistent with Neubert and Halbesleben [31] who investigated the relationship between an employee's job satisfaction and organizational commitment; their findings suggested that there is a positive relationship between a workers' religious affiliation and their organizational satisfaction and commitment; those with religious affiliations tend to have higher organizational satisfaction and commitment.

Assessing minority groups' workplace inclusion and satisfaction by country of birth, the data demonstrated there was no statistically significant difference based on if they were born in the U.S. or not. There were only 117 participants who indicated they were born outside the U.S., therefore, with this a small number of participants, the author is unable to generalize the results to a larger population. These findings are not consistent with the literature on this area, this can be attributed to the small sample size of participants in this study.

The present study's results illustrate a new finding which was that when comparing minority groups engaged in higher education organizations with their minority peers employed at a Historically Black College or University (HBCU) or other minority-serving institutions, minority individuals employed in higher education institutions felt less included and satisfied than the ones involved in HBCU or other minority catering organizations. The study's findings communicate the need for constructing an inclusive climate in the workplace in which workers feel they are an integral part of the organizational fabrics such as access to resources and information networks. Such an inclusive climate could encourage employees to participate in the decision-making process, which in turn may increase their engagement level in workgroups. Employee engagement may well ensure high productivity, low absenteeism, high organizational citizenship, and low turnover rates.

\section{IMPLICATIONS}

The findings of the present study indicated that higher education organizations in the U.S. should pay attention to fostering a climate of inclusion through which organizational structures, systems, and cultures that are consistent with equitable and fair treatment of all social groups with an emphasis on minority groups that have been historically marginalized. Organizational inclusion practices should be implemented to foster a culture of inclusion. For instance, the role of organizational leaders is critical in initiating and advocating using best practices to enhance inclusion. Senior leadership should establish a mechanism through which a pipeline of diverse talent is developed. To ensure retaining the diverse talent, they could retention enact supportive inclusive practices such as creating accountability procedures for inclusion that are integrated within the employer's performance management system [32].

Furthermore, organizational leaders should strive to model behavior that displays an openness and support for pluralistic views as opposed to conformity to pre-established norms by the mainstream. Also, such an organizational leadership should have a system in place to monitor patterns of hiring, promotions, and voluntary turnover of minority employees to ensure there's no deviation from the organization's inclusionary practices, which could assist in fostering a culture of inclusion [33]. Also, higher education organization leaders should establish and take advantage of employee resource groups (ERGs) because these groups are powerful for enhancing socialization and networking opportunities for historically marginalized groups, and many corporations are using them as a catalyst for building inclusive workplaces [16].

Overall, contemporary organizational inclusion best practices underscore the essential role of senior leadership in creating a climate in which all members of the organization feel respected, valued, and being treated respectfully and fairly [16]. Such a role entails establishing equitable systems, structures, and cultures through the adoption of inclusive best practices to ensure attracting, hiring, and retaining top talent.

\section{RECOMMENDATIONS FOR THE FIELD}

Ensuring successful implementation of inclusion initiatives, higher education organizations in the U.S. should shift how inclusion programs are administered to improve organizational processes. These organizations should accentuate on organization development for their inclusion programs to make a lasting change, because organization development is a long-term intervention that is implemented organization wide. According to French and Bell [34], OD is a "long-term effort led and supported by top management, to improve an organization's visioning, empowerment, learning, and problem-solving processes, through an ongoing, collaborative management of organizational culture-with special emphasis on the consultant-facilitator 
role and the theory and technology of applied behavioral science, including participant action research" (p. 380).

Based on the results of this study, HRD professionals working at higher education institutions seem to be using inclusion programs as a stand-alone training endeavor rather than an organization-wide OD intervention. When looking at inclusion programs as a training effort, the goal of that training program is a short-term effort to teach employees basic job skills or develop new skills to ensure closing performance gaps to ensure achieving an organization's goals and objectives. Consequently, OD is an inclusive approach through which input from every stakeholder is sought. Most importantly, if organizations recognize that inclusion programs as an OD effort linked to the organization's strategic goals, such recognition could improve employee engagement, retention, and the organization's competitive edge in this globalized market. In other words, shifting organizational leaders' perspectives on inclusion to ensure that inclusion programs are tied to OD alone wouldn't drive change, but what does that is ensuring these leaders implement an OD bottom-up change where all stakeholders are engaged in the change effort. Inclusion programs are about an organization's culture change through which change agents alter the unspoken and ingrained assumptions of an organization by providing employees with a new experience, because such experience changes the organizational culture.

\section{A. Limitations and Recommendations for Future Research}

This study recruited participants through a voluntary process using MTurk panels. Some of the limitations with utilizing MTurk panels revealed that some respondents were not taking the survey seriously, the researcher decided to take their responses out. Some researchers argued that selfreport data are associated with the validity of the assessments [35], [35]. Hence, the study's participants may consciously or unconsciously felt more inclined to report their experiences based on what they believed to be socially acceptable or describable. Also, the researcher designed the survey to be very inclusive across the demographics, which resulted in small sample sizes for some of the less common demographic groups. There were only 117 participants who indicated they were born outside the U.S., therefore, with this a small number of participants, the author is unable to generalize the results to a larger population. These findings are not consistent with the literature on this area, this can be attributed to the small sample size of participants who were born outside the U.S., in this study. While the sample had over 800 white male responses, for instance, it had a dozen responses for the less common groups. When the decision was made, the researcher was making a tradeoff, because by attempting to make the survey more inclusive to capture a large percentage of smaller groups, the researcher could not satisfactorily analyze the results from the low number of smaller groups. Thus, for future research on this area, the researcher recommends that targeting the smaller groups is essential to ensure that the results and conclusions from the studies are generalizable to the population at large.

\section{CONCLUSION}

The study results demonstrated a new finding which was that minority workers employed at HBCU minority-serving organizations felt more included and satisfied than those minority employees who were engaged in higher education institutions where the mainstream was white male individuals. The present study also contributes to the literature on how perceived inclusion affects minority employees' organizational satisfaction in higher education institutions in the U.S. It also advances the literature in terms of determining the correlation between inclusion and job satisfaction in higher education organizations for minority groups, especially capturing demographics, sexual orientations, and disability statuses of smaller groups. Furthermore, this study is one of the most inclusive studies conducted in relation to minority groups employed in higher education institutions and their perceptions of inclusion and how it impacts their organizational satisfaction in the workplace. The study demonstrated that there is a statistically significant correlation between employee perception of inclusion and their satisfaction in higher education organizations. Groups that do not feel included do not feel satisfied as well. Employees who perceive they are excluded at their place of employment would potentially feel dissatisfied with their employers, which may cause them to resign (Ferris, Brown, Berry, \& Lian, 2008). Therefore, there needs to be an inclusive environment for students, staff, and faculty to achieve a higher education organization's strategic objectives. In the long run, if this change does not occur it would be a lost opportunity for attracting talent and retaining high-performing employees, and may well result in the voluntary turnover of these highperforming workers.

\section{REFERENCES}

[1] Parker, K., Morin, R., \&amp; Horowitz, J. M. (2019, March 21) Public sees America's future in decline on many fronts. Pew Research Center's Social \& Demographic Trends Project. Retrieved December 12, 2020, from https://www.pewresearch.org/socialtrends/2019/03/21/public-sees-an-america-in-decline-on-manyfronts/.

[2] Mitchell, O. S., Blitzstein, D. S., Gordon M., \& Mazo, J. (2003). Benefits for the workplace of the future. (Eds.), Philadelphia, PA: University of Pennsylvania Press.

[3] Hazelkorn, E. (2015). Globalization, internationalization and rankings. International Higher Education, (53) doi:10.6017/ihe.2008.53.8053.

[4] Chun, E., \& Evans, A. (2009). Special issue: Bridging the diversity divide--globalization and reciprocal empowerment in higher education. ASHE Higher Education Report, 35(1), 1. doi:10.1002/aehe.3501.

[5] Bastedo, M, N., Altbach, P, G., Gumport P, J. (2016) American Higher Education in the Twenty-First Century: Social, Political, and Economic Challenges ( $4^{\text {th }}$ ed.). (Eds.), Baltimore, MD: Johns Hopkins University Press.

[6] Wilson, V. (2016). People of color will be a majority of the American working class in 2032: What this means for the effort to grow wages and reduce inequality. Retrieved from http:// www.epi.org/publication/the-changing-demographics-of-americasworking-class/

[7] United Nations, Department of Economic and Social Affairs. (2015) World population prospects: The 2015 revision: Key findings and advance tables. $\quad$ Retrieved from https://esa. un.org/Unpd/wpp/Publications/Files/Key_Findings_WPP_2015.pdf.

[8] Kuchinke, K. P. (2010). Human development as a central goal for human resource development. Human Resource Development International, 13, 575-585. 
[9] Shore, L. M., Randel, A. E., Chung, B. G., Dean, M. A., Holcombe Ehrhart, K., \& Singh, G. (2011). Inclusion and Diversity in Work Groups: A Review and Model for Future Research. Journal of Management, 37(4), 1262-1289. doi:10.1177/0149206310385943.

[10] Mor-Barak, M. E. (2017c). Managing diversity: Toward a globally inclusive workplace (Fourth ed.). Los Angeles: SAGE Publications, Inc.

[11] Ferdman, B.M. and Deane, B.R. (Eds) (2013), Diversity at Work: The Practice of Inclusion. Jossey-Bass: San Francisco, CA.

[12] Mor-Barak, M. E. (2014b). Managing diversity: Toward a globally inclusive workplace (Third ed.). Thousand Oaks: SAGE Publications.

[13] Ferdman, B. M. (2017). Paradoxes of inclusion: Understanding and managing the tensions of diversity and multiculturalism. Journal of Applied Behavioral Science, 53(2), 235-263. doi:10.1177/0021886317702608.

[14] Mor Barak, M. E. (2000a). The inclusive workplace: An ecosystems approach to diversity management. Social Work, 45(4), 339-353. doi:10.1093/sw/45.4.339.

[15] Nishii, L. H., \& Rich, R. E. (2014). Creating inclusive climates in diverse organizations. In B. M.

[16] Shore, L. M., Cleveland, J. N., \& Sanchez, D. (2018). Inclusive workplaces: A review and model. Human Resource Management Review, 28(2), 176-189. doi:10.1016/j.hrmr.2017.07.003.

[17] Bhopal, K., \& Rhamie, J. (2014). Initial teacher training: Understanding 'race,' diversity and inclusion. Race Ethnicity and Education, 17(3), 304-325. doi:10.1080/13613324.2013.83292.

[18] Tienda, M. (2013). Diversityłinclusion: Promoting integration in higher education. Educational Researcher, 42(9), 467-475. doi:10.3102/0013189X13516164.

[19] Sørensen, J. (2004). The organizational demography of racial employment segregation. The American Journal of Sociology, 110(3), 626-671. doi:10.1086/426464.

[20] Hornsey, M. J. (2008). Social identity theory and self-categorization theory: A historical review. Social and Personality Psychology Compass, 2(1), 204-222. doi:10.1111/j.1751-9004.2007.00066.x.

[21] Burnham, C. (2017). Self and social identity in educational contexts. Educational Psychology in Practice, 33(4), 450-451. doi:10.1080/02667363.2017.1344493.

[22] Hewapathirana, G. (2012). Organizational leaders' social identity: a basis for employer-employee motivation in small organizations in Sri Lanka. Human Resource Development International, 15(4), 489-499. doi:10.1080/13678868.2012.690970.

[23] Ryan, R. M., \& Deci, E. L. (2017) Self-determination theory basic psychological needs in motivation, development, and wellness. New York, NY: The Guilford Press.

[24] Buhrmester, M., Kwang, T., \& Gosling, S. D. (2011). Amazon's mechanical turk: A new source of inexpensive, yet high-quality, data? Perspectives on Psychological Science, 6(1), 3-5. doi:10.1177/1745691610393980.

[25] Mason, W., \& Suri, S. (2012). Conducting behavioral research on amazon's mechanical turk. Behavior Research Methods (Online), 44(1), 1-23.

[26] National Center for Education Statistics. (2019, May). The Condition of Education 2019. nces.ed.gov. Retrieved December 6, 2020, from https://nces.ed.gov/pubs2019/2019144.pdf.

[27] Mor Barak ME (2005) Managing diversity: Toward a globally inclusive workplace. Sage, Thousand Oaks, CA

[28] United States Census Bureau (2017). How Disability Data are Collected from The American. Retrieved from https://www.census.gov/topics/health/disability/guidance/datacollection-acs.html.

[29] Smith, J. W., \& Calasanti, T. (2005). the influences of gender, race and ethnicity on workplace experiences of institutional and social isolation: An exploratory study of university faculty. Sociological Spectrum, 25(3), 307-334. doi:10.1080/027321790518735.

[30] Byrd, K. R., Lear, D., \& Schwenka, S. (2000). Mysticism as a predictor of subjective well-being. The International Journal for the Psychology of Religion, 10(4), 259-269

[31] Neubert, M. J., \& Halbesleben, K. (2015). Called to commitment: An examination of relationships between spiritual calling, job satisfaction, and organizational commitment: JBE JBE. Journal of Business Ethics, 132(4), 859-872.

[32] Offerman, L. R., \& Basford, T. E. (2014). Best practices and the changing role of human resources. In B. M. Ferdman, \& B. R. Deane (Eds.), Diversity at work: The practice of inclusion. San Francisco, CA: Jossey-Bass.

[33] Gallegos, P. V. (2014). The work of inclusive leadership. In B. M. Ferdman, \& B. R. Deane (Eds.), Diversity at work: The practice of inclusion. San Francisco, CA: Jossey-Bass.
French, W. L., \& Bell, C. H. (1999). Organization development: Behavioral science interventions for organization improvement. (6th ed.). Upper Saddle River: Prentice-Hall, Inc.

[34] Kuncel, N. R., and Tellegen, A. (2009). A conceptual and empirical reexamination of the measurement of the social desirability of items: implications for detecting desirable response style and scale development. Pers. Psychol. 62, 201-228. doi:10.1111/j.17446570.2009.01136.x.

[35] Weijters, B., Baumgartner, H., and Schillewaert, N. (2013). Reversed item bias: an integrative model. Psychol. Methods, 18, 320-334. doi: $10.1037 / \mathrm{a} 0032121$

[36] Abdul-Raheem, J. (2016). Faculty diversity and tenure in higher education. Journal of Cultural Diversity, 23(2), 53.

[37] Acquavita, S. P., Pittman, J., Gibbons, M., \& Castellanos-Brown, K. (2009). Personal and organizational diversity factors' impact on social workers' job satisfaction: Results from a national internet-based survey. Administration in Social Work, 33(2), 151-166. doi:10.1080/03643100902768824.

[38] Bilimoria, D., Joy, S., \& Liang, X. (2008). Breaking barriers and creating inclusiveness: Lessons of organizational transformation to advance women faculty in academic science and engineering. Human Resource Management, 47(3), 423-441. doi:10.1002/hrm.20225.

[39] Bowling, N. A., \& Hammond, G. D. (2008). A meta-analytic examination of the construct validity of the Michigan Organizational Assessment Questionnaire job satisfaction subscale. Journal of Vocational Behavior, 73(1), 63-77. doi:10.1016/j.jvb.2008.01.004.

[40] Bortree, D. S., Waters, R. D. (2008). The value of feeling included: The impact of inclusion on teen volunteers' organizational satisfaction. International Journal of Volunteer. Retrieved from https://www.researchgate.net/profile/Richard_Waters/publication/242 268244_The_Value_of_Feeling_Included_The_Impact_of_Inclusion_ on_Teen_Volunteers\%27_Organizational_Satisfaction/links/00b7d52 dec7a4268ce000000/The-Value-of-Feeling-Included-The-Impact-ofInclusion-on-Teen-Volunteers-Organizational-Satisfaction.pdf

[41] Brooks, A. K., \& Edwards, K. (2009). Allies in the workplace: Including LGBT in HRD. Advances in Developing Human Resources, 11(1), 136-149. doi:10.1177/1523422308328500

[42] Clotfelter, C. T., Ehrenberg, R. G., Getz, M., Siegfried, J. J. (1992) Economic challenges in higher education ( $1^{\text {st }}$ ed.). Chicago, IL: University of Chicago Press.

[43] Consortium of Higher Education ( n.d.). LGBT Resource Professionals. (2019, September 26) Retrieved from: https://www.lgbtcampus.org/assets/docs/suggested\%20best\%20practi ces\%20for\%20asking\%20sexual\%20orientation\%20and\%20gender\% 20on\%20college\%20applications.pdf

[44] Fox, C. (2018, May 1). Work Institute Release National Employee Retention Report. Retrieved September 28, 2019, from https://workinstitute.com/about-us/news-events/articleid/2259/2018 retention report.

[45] Ferris, D. L., Brown, D. J., Berry, J. W., \& Lian, H. (2008). The development and validation of the workplace ostracism scale. Journal of Applied Psychology, 93(6), 1348-1366. doi:10.1037/a0012743.

[46] Halkos, G., \& Bousinakis, D. (2010). The effect of stress and satisfaction on productivity. International Journal of Productivity and $\begin{array}{llr}\text { Performance } \quad \text { Management, } & \text { 59(5), }\end{array}$ dx.doi:/10.1108/17410401011052869.

[47] Herget, A. (2016, August 18). Foreign-Born Faculty Face Challenges. Retrieved from: https://www.higheredjobs.com/articles/articleDisplay.cfm?ID=1012.

[48] Heslop, P., Davey Smith, G., Metcalfe, C., Macleod, J., \& Hart, C. (2002). Change in job satisfaction, and its association with selfreported stress, cardiovascular risk factors and mortality. Social Science \& Medicine, 54(10), 1589-1599. doi:10.1016/S02779536(01)00138-1.

[49] Hiltrop, J. (1999). The quest for the best: Human resource practices to attract and retain talent. European Management Journal, 17(4), 422430. doi:10.1016/S0263-2373(99)00022-5.

[50] Hurtado, S., \& Ponjuan, L. (2005). Latino educational outcomes and the campus climate. Journal of Hispanic Higher Education, 4(3), 235251. doi:10.1177/1538192705276548.

[51] Lawler, E. E., \& Porter, L. W. (1967). The effect of performance on job satisfaction. Industrial Relations: A Journal of Economy and Society, 7(1), 20-28. doi:10.1111/j.1468-232X.1967.tb01060.x.

[52] Lee, T., \& Mitchell, T. (1994). An alternative approach - the unfolding model of voluntary employee turnover. Academy of

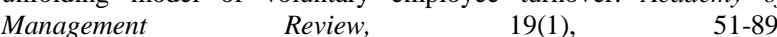
doi:10.5465/AMR.1994.9410122008

[53] Lloyd-Jones, B. (2009). Implications of race and gender in higher education administration: An African American woman's perspective. 
Advances in Developing Human Resources, 11(5), 606-618. doi:10.1177/1523422309351820.

[54] Keller, G. (2001). The new demographics of higher education. The Review of Higher Education, 24(3), 219-235. doi:10.1353/rhe.2001.0004

[55] Locke, E. A. (1976). The nature and causes of job satisfaction. In M. D. Dunnette (Ed.), Handbook of industrial and organizational psychology (pp. 1297-1349). Chicago, IL: Rand McNally.

[56] Jansen, W. S., Otten, S., van der Zee, Karen I, \& Jans, L. (2014). Inclusion: Conceptualization and measurement. European Journal of Social Psychology, 44(4), 370-385. doi:10.1002/ejsp.2011.

[57] Maslow, A. H. (1943). A theory of human motivation. Psychological Review, 50(4), 370-396. doi: 10.1037/h0054346.

[58] Myerson, J., Bichard, J., \& Erlich, A. (2016). New demographics, new workspace: Office design for the changing workforce. London, U.K: Routledge.

[59] Ferdman, \& B. R. Deane (Eds.), Diversity at work: The practice of inclusion (pp. 205-228). San Francisco, CA: Jossey-Bass.

[60] Pelled, L., Ledford, G., Mohrman, S. (1999). Demographic dissimilarity and workplace inclusion. Journal of Management Studies, 36(7), 1013-1031. doi:10.1111/1467-6486.00168.

[61] Quaye, S. J. (2012). White Educators Facilitating Discussions About Racial Realities. Equity and Excellence in Education, 45(1), 100-119.

[62] Sherbin, L., \& Rashid, R. (2017). Diversity Doesn't Stick Without Inclusion. Harvard Business Review. Retrieved October 10, 2017, from https://www.cof.org/sites/default/files/documents/files/HBR Diversity Doesn't Stick Without Inclusion - Sherbin \& Rashid_2.1.17...pdf.

[63] Smyth, R., Zhai, Q., \& Li, X. (2009). Determinants of turnover intentions among Chinese off farm migrants. Economic Change and Restructuring, 42(3), 189-209. doi:10.1007/s10644-008-9067-z.

[64] Society for Human Resource Management. (2019). SHRM Learning System. Alexandria, VA.

[65] Tsui, A. S., \& Gutek, B. A. (1999). Demographic differences in organizations: Current research and future directions. Lanham, MD: Lexington Books.

[66] Tajfel, H. (1972). Social categorization. English manuscript of 'La categorisation sociale.' In S. Moscovici (Ed.), Introduction a la Psychologie Sociale, (1), 272-302. Paris: Larousse.

[67] Tajfel, H., \& Turner, J. C. (1979). An integrative theory of intergroup conflict. In W. G. Austin \& S. Worchel (Eds.), The psychology of intergroup relations (pp. 33-47). Pacific Grove, CA: Brooks/Cole.

[68] Tajfel, H. and Turner, J.C. (1986) The social identity theory of intergroup behaviour, in S.Worchel and W.G.Austin (eds) Psychology of Intergroup Relations, Chicago: Nelson-Hall.

[69] U.S. Bureau of Labor Statistics. (2015). Women in the labor force: A databook. Retrieved from https://www.bls.gov/opub/reports/womensdatabook/archive/women-in-the-labor-force-adatabook-2015.pdf. 